\title{
Factors Influencing Family Physicians' Contribution to the Child Health Care Workforce
}

Laura A. Makaroff, DO'

Imam M. Xierali, $P b D^{2}$

Stephen M. Petterson, $\mathrm{PbD}, \mathrm{MPH}^{1}$

Scott A. Shipman, MD, MPH

James C. Puffer, $M D^{4}$

Andrew W. Bazemore, MD, MPH

'The Robert Graham Center: Policy Studies in Family Medicine and Primary Care, Washington, DC

${ }^{2}$ Association of American Medical Colleges, Washington, DC

${ }^{3}$ Dartmouth Institute for Health Policy and Clinical Practice, Lebanon, New Hampshire

${ }^{4}$ The American Board of Family Medicine, Lexington, Kentucky

Conflicts of interest: authors report none.

\section{CORRESPONDING AUTHOR}

Andrew Bazemore, MD, MPH

The Robert Graham Center

1133 Connecticut Ave, Suite 1100

Washington, DC 20036

policy@aafp.org

\begin{abstract}
PURPOSE We wanted to explore demographic and geographic factors associated with family physicians' provision of care to children.

METHODS We analyzed the proportion of family physicians providing care to children using survey data collected by the American Board of Family Medicine from 2006 to 2009. Using a cross-sectional study design and logistic regression analysis, we examined the association of various physician demographic and geographic factors and providing care of children.
\end{abstract}

RESULTS Younger age, female sex, and rural location are positive predictors of family physicians providing care to children: odds ratio $(\mathrm{OR})=0.97(95 \% \mathrm{Cl}$, $0.97-0.98), 1.19$ (1.12-1.25), and 1.50 (1.39-1.62), respectively. Family physicians practicing in a partnership are more likely to provide care to children than those in group practice: $\mathrm{OR}=1.53(95 \% \mathrm{Cl}, 1.40-1.68)$. Family physicians practicing in areas with higher density of children are more likely to provide care to children: $\mathrm{OR}=1.04(95 \% \mathrm{Cl}, 1.03-1.05)$, while those in high-poverty areas are less likely $0.10(95 \% \mathrm{Cl}, 0.10-0.10)$. Family physicians located in areas with no pediatricians are more likely to provide care to children than those in areas with higher pediatrician density: $\mathrm{OR}=1.80(95 \% \mathrm{Cl}, 1.59-2.01)$.

CONCLUSIONS Various demographic and geographic factors influence the likelihood of family physicians providing care to children, findings that have important implications to policy efforts aimed at ensuring access to care for children.

Ann Fam Med 2014;12:427-431. doi: 10.1370/afm.1689.

\section{INTRODUCTION}

$\mathrm{P}$ olicy discussions regarding looming physician shortages and the implementation of health care reform have focused predominantly on adults. The costs of adult-related health care can overwhelm those of children's care, leaving children's health services to be an afterthought in the minds of many policy makers. Yet children and families often face difficulties in accessing primary health care services. Previous evidence has shown that 1 in 10 children experience unmet health care needs; unmet needs worsen to 1 in 3 for those children without health insurance. ${ }^{1}$ Children with a usual source of care have better health outcomes, including more preventive health counseling and fewer avoidable hospitalizations, than children who do not. ${ }^{2-4}$ Furthermore, access to patient-centered, comprehensive primary care has been shown to improve delivery of preventive services and decrease unmet medical needs of children.,

Pediatricians and family physicians make up the majority of the current physician workforce responsible for providing primary care for children. While pediatricians account for a large proportion of physician visits by children, family physicians are named as the usual source of care for one-third of the child population and provide $16 \%$ to $21 \%$ of physician visits by children. ${ }^{1}$ Given the important role of family physicians, the recent trend of narrowing family physician scope of practice is of concern. ${ }^{7,8} \mathrm{~A}$ recent update showed that family physicians continue 
to spend approximately $10 \%$ of their practice time providing care for children. However, the absolute proportion of family physicians providing any care to children declined from $78 \%$ in 2000 to $68 \%$ in $2009 .{ }^{9}$ It is important to better understand factors associated with this decline given the importance of ensuring access to primary care for all children. Therefore, we sought to explore the demographic and geographic characteristics of family physicians who provide care for children using a unique census of American Board of Family Medicine Diplomates.

\section{METHODS}

This cross-sectional study uses data collected from all family physicians who took the American Board of Family Medicine (ABFM) Maintenance of Certification (MOC) Examination between 2006 and 2009. Approximately 82,000 family physicians are certified by the ABFM. Ninety-one percent of all eligible, active, board-certified family physicians participate in MOC. ${ }^{10}$ Demographic and practice characteristics of all Diplomates are collected by the ABFM at the time of application for the recertification examination. This yearly survey is unique in that it has a $100 \%$ response rate, since candidates are required to answer the census questions before they can successfully complete the exam application. A total of 37,020 Diplomates were recertified by the ABFM during the period 2006 to 2009-approximately 45\% of all Diplomates.

The ABFM survey includes a mandatory question that asks family physicians to estimate the percentage of their time "by type of practice or professional activity" for 24 practice and professional activities, one of which is "care of children." No explanation of the term care of children is provided on the survey, and candidates respond based on their own interpretation of the question. We added more demographic and geographic characteristics of the 2006-2009 cohorts by linking the ABFM data to the American Medical Association Physician Masterfile. We geocoded ABFM Diplomate address data in ArcGIS version 9.3 (ESRI) and linked to US Census 2000 tabulations, the 2003 Rural Urban Continuum Codes, and the Primary Care Service Areas (PCSA).

We defined the outcome as a dichotomous variable, with responses of more than $0 \%$ of time spent in providing care to children coded as 1 and others coded as 0 . We then built a logistic regression model to examine the association between provision of care for children and the characteristics of physicians and their practices. Variables in the model include physician age, sex, type of physician practice, federally-defined poverty level, rural or urban indicator, percent of the popula- tion aged 18 years or younger, year of test registration, International medical graduates (IMG)/non-IMG, and region of the United States where the physician practices. To measure the supply of pediatricians and explore possible substitution effects between family physicians and pediatricians, we also included PCSAlevel density of pediatricians per capita. Pediatrician density was dissected to quintiles. The lowest quintile was further subdivided into 2 categories-PCSAs with no pediatricians at all vs others-resulting in a 6-category measure.

Prenatal care, obstetric deliveries, and care of newborns are all reported variables within the ABFM survey. Each of these activities is highly correlated with providing care to children and was therefore dropped from the analysis to avoid confounding.

\section{RESULTS}

The overall proportion of family physicians providing care to children declined from $74 \%$ in 2006 and 2007 to $72 \%$ in 2008 and $68 \%$ in 2009 (Table 1). This decline in the proportion of family physicians providing care of children is consistent across multiple demographic characteristics including application year, physician age and sex, practice organization type, rural area, high poverty areas, and census regions.

Regression results (Table 2) show the following:

- As physician age increases, the likelihood that the physician reports providing care for children decreases: $\mathrm{OR}=0.97$ (95\% CI, 0.97-0.97).

- Female physicians are more likely to provide care for children than male physicians: $\mathrm{OR}=1.19$ (95\% CI, 1.12-1.25).

- As year of application for the recertification exam increases, the likelihood that the physician provides care for children decreases.

- International Medical Graduates are less likely to provide care for children: $\mathrm{OR}=0.88$ (95\% CI, 0.8-0.94).

- Family physicians in partnership practice are more likely to provide care of children than those in group practice: $\mathrm{OR}=1.53$ (95\% CI, 1.40-1.68).

- Those in HMO or government settings are less likely to provide care to children than those in group practice: $\mathrm{OR}=0.39(95 \% \mathrm{CI}, 0.35-0.45)$ and $0.26(95 \%$ CI, 0.24-0.29), respectively.

- Family physicians practicing in rural areas and areas with a higher population percentage of children aged 18 years or younger are more likely to provide care to children: $\mathrm{OR}=1.50$ (95\% CI, 1.39-1.62) and 1.04 (95\% CI, 1.03-1.05), respectively.

- Family physicians practicing in areas with few or no pediatricians per capita are more likely to provide care for children. 
There are also significant regional differences. Family physicians in the South and West regions of the United States are less likely to provide care for children than family physicians in the Northeast. Further analysis shows a strong state-level variation in the proportion of family physicians providing care to children, with a low of $45 \%$ in the District of Columbia and a high of $84 \%$ in Nebraska (Figure 1). Similarly, analysis shows that the presence of family physicians substantially decreases the number of PCSAs with no child health providers and increases the proportion of PCSAs with more than 1 child health physician per 3,000 children (Supplemental Figures 1 and 2, available in a separate appendix). The number of PCSAs with adequate physician supply, defined as greater than 1 child health physician per 3,000 children, increases from 2,000 with only pediatricians included to 4,362 with pediatricians and family physicians included.

\section{Table 1. Descriptive Statistics of Family Physicians Providing Care to Children, 2006-2009}

\begin{tabular}{|c|c|c|c|c|c|c|c|c|}
\hline \multirow[b]{2}{*}{ Characteristic } & \multicolumn{2}{|c|}{2006} & \multicolumn{2}{|c|}{2007} & \multicolumn{2}{|c|}{2008} & \multicolumn{2}{|c|}{2009} \\
\hline & No. & $\%{ }^{a}$ & No. & $\%{ }^{a}$ & No. & $\%{ }^{a}$ & No. & $\%{ }^{a}$ \\
\hline All respondents & 8,263 & 74 & 9,507 & 74 & 9,692 & 72 & 9,558 & 68 \\
\hline \multicolumn{9}{|l|}{ Sex } \\
\hline Female & 2,632 & 77 & 3,146 & 75 & 3,218 & 72 & 3,324 & 71 \\
\hline Male & 5,631 & 73 & 6,361 & 73 & 6,474 & 72 & 6,234 & 67 \\
\hline \multicolumn{9}{|l|}{ Age-group } \\
\hline$<40 y$ & 1,868 & 82 & 2,095 & 81 & 1,877 & 79 & 1,580 & 76 \\
\hline $40-60 y$ & 5,749 & 73 & 6,522 & 73 & 6,739 & 71 & 6,717 & 68 \\
\hline$>60 y$ & 646 & 65 & 890 & 62 & 1,076 & 62 & 1,261 & 62 \\
\hline $\begin{array}{l}\text { International med- } \\
\text { ical graduate }\end{array}$ & 865 & 73 & 1,142 & 67 & 1,297 & 65 & 1,457 & 67 \\
\hline \multicolumn{9}{|l|}{ Organization type } \\
\hline Administration & 91 & 13 & 105 & 11 & 111 & 7 & 101 & 5 \\
\hline Educator & 438 & 83 & 493 & 73 & 456 & 74 & 460 & 73 \\
\hline Government & 512 & 48 & 634 & 50 & 698 & 49 & 681 & 43 \\
\hline Group & 3,580 & 80 & 4,138 & 80 & 4,249 & 78 & 4,116 & 75 \\
\hline $\mathrm{HMO}$ & 277 & 57 & 315 & 58 & 298 & 58 & 287 & 56 \\
\hline Solo & 1,548 & 77 & 1,786 & 78 & 1,859 & 74 & 1,914 & 71 \\
\hline Other & 736 & 47 & 829 & 48 & 895 & 49 & 921 & 47 \\
\hline Partnership & 1,081 & 86 & 1,207 & 85 & 1,126 & 86 & 1,078 & 81 \\
\hline Rural & 1,598 & 82 & 1,720 & 82 & 1,821 & 81 & 1,744 & 76 \\
\hline High poverty areab & 3,960 & 76 & 4,595 & 76 & 4,586 & 74 & 4,552 & 70 \\
\hline \multicolumn{9}{|l|}{ Census region } \\
\hline Northeast & 1,213 & 74 & 1,399 & 76 & 1,392 & 74 & 1,374 & 71 \\
\hline Midwest & 2,233 & 80 & 2,529 & 78 & 2,555 & 74 & 2,453 & 71 \\
\hline South & 2,765 & 71 & 3,167 & 70 & 330 & 68 & 3,243 & 64 \\
\hline West & 1,980 & 73 & 2,336 & 73 & 2,352 & 70 & 2,407 & 67 \\
\hline \multicolumn{9}{|c|}{ Note: $P<.01$} \\
\hline \multicolumn{9}{|c|}{$\mathrm{HMO}=$ health maintenance organization. } \\
\hline \multicolumn{9}{|c|}{ a Percentage of those in the indicated category who provide care for children. } \\
\hline
\end{tabular}

\section{DISCUSSION}

The decline in the provision of care to children by family physicians adds complexity to the general debate about whether the physician supply is adequate or whether we face a looming physician shortage. ${ }^{11,12}$ Child health care physician supply and capacity are likely to be further stretched by current health reform efforts that promise increased health insurance coverage for children and adults. Family physicians, especially in rural and underserved areas, may face impossible demands to care for a larger insured population, resulting in decreased capacity to provide care for children. Additionally, current geographic maldistribution of the child health care physician workforce is leading to difficulty with access to care for many children and families. ${ }^{13}$

Fostering medical student interest in family medicine and pediatrics is an important first step in strengthening the primary care child health physician workforce. Future policy aimed at reducing medical student debt load and increased attention to the work-life balance of primary care physicians may help bolster medical student interest in both family medicine and pediatrics. ${ }^{14}$

In preliminary analyses, we also found that family physicians who provide care of children are more likely to provide maternity care. This association highlights several points for policy makers to keep in mind:

- Obstetric and perinatal training are important elements of family medicine residencies if family physicians are to care for children.

- Policies may need to support the diminishing number of family physicians who wish to maintain maternity care in their practices.

- Further exploration of the adequacy of pediatric training in family medicine residencies may be important if maintaining comprehensive scope of practice among practicing family physicians remains a priority.

- Strengthening existing partnerships and forging new collaborative relationships among general pediatric, obstetric, and family medicine educators may also be 
important if we are to ensure a well-trained, geographically well-distributed child physician workforce.
- Policy makers must consider how ongoing discussions of payment reforms, principally aimed at valuebased purchasing and broader population manage-

Table 2. Logistic Regression Odds Ratios Predicting Family Physicians Providing Care of Children

\begin{tabular}{|c|c|c|c|c|c|}
\hline Variable & OR & $95 \% \mathrm{CL}$ & Variable & OR & $95 \% \mathrm{CL}$ \\
\hline Age $^{a}$ & 0.97 & $0.97,0.98$ & Percent population $<18 \mathrm{y}^{\mathrm{a}}$ & 1.04 & $1.03,1.05$ \\
\hline Female (reference $=$ male) & 1.19 & $1.12,1.25$ & High-poverty area (reference = Non-high- & 0.10 & $0.10,0.10$ \\
\hline \multicolumn{3}{|l|}{ Application year (ref = 2006) } & \multicolumn{3}{|l|}{ Pediatrician density (reference $=5$ th quintile) } \\
\hline 2008 & 0.92 & $0.85,0.98$ & No pediatricians & 1.79 & $1.59,2.01$ \\
\hline 2009 & 0.79 & $0.74,0.85$ & 1st quintile & 1.26 & $1.14,1.40$ \\
\hline \multirow{2}{*}{$\begin{array}{l}\text { International medical graduate (IMG; } \\
\text { reference = non-IMG) }\end{array}$} & \multirow[t]{2}{*}{0.88} & \multirow{2}{*}{$0.81,0.94$} & 2nd quintile & 1.29 & $1.19,1.40$ \\
\hline & & & 3rd quintile & 1.13 & $1.05,1.22$ \\
\hline Rural (reference $=$ urban) & 1.50 & $1.39,1.62$ & 4th quintile & 1.03 & $0.96,1.10$ \\
\hline \multicolumn{3}{|c|}{ Organization type (reference = group practice) } & \multicolumn{3}{|l|}{ Census regions (reference $=$ Northeast) } \\
\hline Administration & 0.03 & $0.02,0.05$ & Midwest & 0.95 & $0.87,1.03$ \\
\hline Educator & 1.06 & $0.94,1.19$ & South & 0.68 & $0.63,0.74$ \\
\hline Government & 0.26 & $0.24,0.29$ & West & 0.89 & $0.82,0.97$ \\
\hline $\mathrm{HMO}$ & 0.39 & $0.35,0.45$ & & & \\
\hline Independent (solo) & 0.98 & $0.92,1.06$ & & & \\
\hline Other & 0.26 & $0.24,0.28$ & & & \\
\hline Partnership & 1.53 & $1.40,1.68$ & & & \\
\hline
\end{tabular}

$\mathrm{CL}=$ confidence limits; $\mathrm{IMG}=$ international medical graduate; $\mathrm{HMO}=$ health maintenance organization.

${ }^{a}$ Continuous variable.

${ }^{b}$ Community where $>20 \%$ of population is at or below $200 \%$ of the federal poverty level.

\section{Figure 1. Proportion of family physicians providing care of children, 2006-2009.}

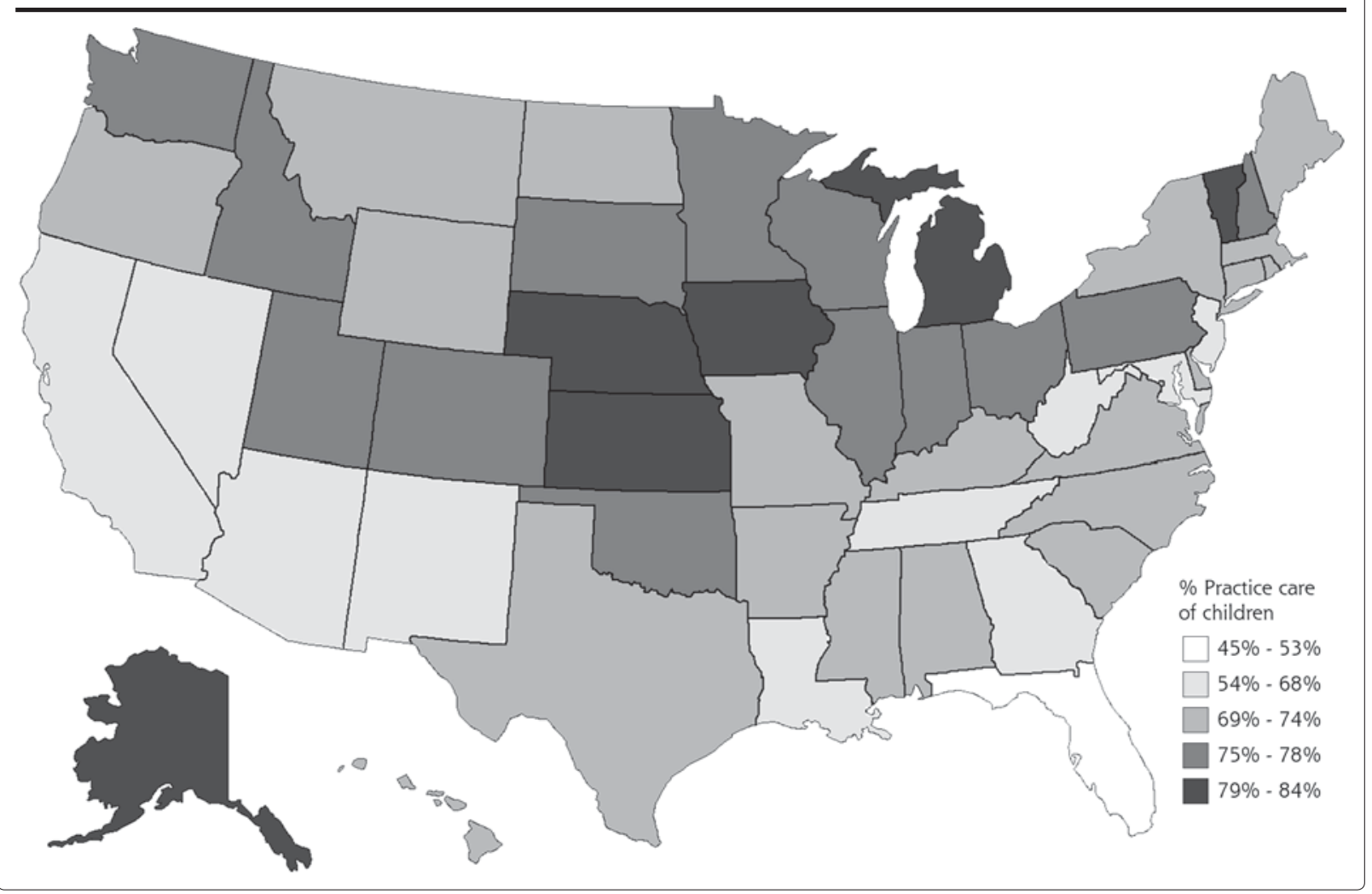


ment, influence access to care for children in areas with few providers.

This study has several limitations. First, while the strength of the ABFM source is that all participants in MOC must answer the survey questions, it remains subject to reporting and recall biases. Survey data are collected from each Diplomate every 7 to 10 years, so each year's data are at best a representative sample of the entire population of family physicians. Our analyses in this study are a series of cross-sectional observations from 4 study years. The necessary dichotomization of care of children by family physicians to be all or nothing is another limitation. Still, we believe that the ABFM source is the best available to identify variations in scope-of-practice patterns overall.

Family physicians offer unique contributions to the care of US children, for whom they are the vanguard of access in many rural, urban, and underserved areas. Policy makers and leaders in the pediatric workforce community concerned with providing adequate and accessible care to children and families must help family physicians manage the burdens of increasing demands and incentives to care for adults, amidst shifting physician demographics and fluctuating interest in primary care.

To read or post commentaries in response to this article, see it online at http://www.annfammed.org/content/12/5/427.

Key words: workforce; pediatrics; family physicians; children

Submitted January 10, 2014; submitted, revised, May 13, 2014; accepted June 9, 2014.

Disclaimer: The information and opinions contained in research from the Graham Center do not necessarily reflect the views or policy of the American Academy of Family Physicians. The corresponding author had full access to all the data in the study and takes responsibility for the integrity of the data and the accuracy of the data analysis.

Acknowledgments: We gratefully acknowledge the contributions of Warren Newton, MD, to the ideas and discussions that helped to shape this study and its publication.

Supplementary materials: Available at http://www.AnnFamMed. org/content/12/5/427/suppl/DC1/

\section{References}

1. Phillips RL, Dodoo MS, McCann JL, et al. Report to the Task Force on the Care of Children by Family Physicians. Washington, DC: The Robert Graham Center for Policy Studies in Family Medicine and Primary Care in collaboration with the American Academy of Pediatrics Center for Child Health Research; 2005.

2. Devoe JE, Tillotson CJ, Wallace LS, Lesko SE, Pandhi N. Is health insurance enough? A usual source of care may be more important to ensure a child receives preventive health counseling. Matern Child Health J. 2011;16(2):306-315.

3. DeVoe JE, Ray M, Krois L, Carlson MJ. Uncertain health insurance coverage and unmet children's health care needs. Fam Med. 2010;42(2):121-132

4. Tom JO, Tseng CW, Davis J, Solomon C, Zhou C, Mangione-Smith R. Missed well-child care visits, low continuity of care, and risk of ambulatory care-sensitive hospitalizations in young children. Arch Pediatr Adolesc Med. 2010;164(11):1052-1058.

5. Strickland BB, Jones JR, Ghandour RM, Kogan MD, Newacheck PW The medical home: health care access and impact for children and youth in the United States. Pediatrics. 2011;127(4):604-611.

6. Devoe JE, Tillotson CJ, Wallace LS, Lesko SE, Angier H. The effects of health insurance and a usual source of care on a child's receipt of health care. J Pediatr Health Care. 2012;26(5):e25-e35.

7. Bazemore AW, Petterson S, Johnson N, et al. What services do family physicians provide in a time of primary care transition? J Am Board Fam Med. 2011;24(6):635-636.

8. Bazemore AW, Phillips RL, Dodoo MS, McCann J, Klein LS, Green LA; Robert Graham Center: Policy Studies in Family Medicine and Primary Care. The diminishing role of FPs in caring for children. Am Fam Physician. 2006;73(9):1518.

9. Bazemore AW, Makaroff LA, Puffer JC, et al. Declining numbers of family physicians are caring for children. J Am Board Fam Med. 2012;25(2):139-140.

10. Xierali IM, Rinaldo JC, Green LA, et al. Family physician participation in maintenance of certification. Ann Fam Med. 2011;9(3): 203-210.

11. Colwill JM, Cultice JM, Kruse RL. Will generalist physician supply meet demands of an increasing and aging population? Health Aff (Millwood). 2008;27(3):w232-w241.

12. Petterson SM, Liaw WR, Phillips RL Jr, Rabin DL, Meyers DS, Bazemore AW. Projecting US primary care physician workforce needs: 2010-2025. Ann Fam Med. 2012;10(6):503-509.

13. Shipman SA, Lan J, Chang C, Goodman DC. Geographic maldistribution of primary care for children. Pediatrics. 2011;127(1):19-27.

14. Bennett KL, Phillips JP. Finding, recruiting, and sustaining the future primary care physician workforce: a new theoretical model of specialty choice process. Acad Med. 2010;85(10)(Suppl):S81-S88.

15. Green LA, Jones SM, Fetter G Jr, Pugno PA. Preparing the personal physician for practice: changing family medicine residency training to enable new model practice. Acad Med. 2007;82(12):1220-1227. 